\title{
ROLE OF ELECTRICAL STIMULATION ADDED TO CONVENTIONAL THERAPY IN PATIENTS WITH TRAUMATIC FACIAL PALSY
}

\author{
Authors: Sanyukta Chakravorty*(1), Sumit Sharma (2), Suvarna Sharma (3) \\ Authors Affiliations: (1) Postgraduate Junior Resident second year; (2) Professor \& Head, Department of \\ E.N.T., Mayo Institute of Medical Sciences, Barabanki, UP, India, (3) 4th Year MBBS student, KMC Manipal.
}

\begin{abstract}
Background: Facial nerve palsy can have ophthalmological, Otological, rhinological, taste, and swallowing consequences, in addition to the psychological impact of altered facial expression. Electrical Stimulation (ES) is one of the most debatable and non-evidence-based adjunctive therapies for facial palsy.
\end{abstract}

\section{MATERIAL/METHODS}

We retrieved the literature on ES in facial nerve injury using the Cochrane Database of Systematic Reviews, PubMed, and Google Scholar. Emphasis was placed on articles and randomised controlled trials (RCTs) published within the last 20 years.

Results: The reviewed studies, clinical trials and systematic reviews did not support ES due to a lack of quality evidence to support significant benefit or harm from ES. The varied methodologies used and the small number of subjects included in the studies could not wholly prove the efficacy of electrotherapy for treating facial nerve injury.

\section{CONCLUSION}

Though many studies have reported improvement of facial movement or function following ES for facial nerve injury, substantial evidence supporting the use of ES in facial palsy is lacking; well-designed rigorous research is required.

\section{KEYWORDS}

Electrical Stimulation, Facial Nerve Palsy, Facial Paralysis

\section{INTRODUCTION}

The facial nerve (CN VII) plays a crucial role in several complex and routine functions such as speech, mastication and effective social communication through the expression of mood and emotion. Central facial palsy (CFP) occurs due to damage to the central segment of this nerve (facial nucleus in the pons, motor cortex, or connections between the two). It manifests classically as a one-sided impairment of movement opposite to the side of the injury, with predominance in the lower part of the face. CFP is a common initial sign in patients after stroke and other neurological injuries. Natural recovery of CFP has been reported in two-thirds of people within six months of a stroke. Approximately onethird of patients after stroke continue to present with persisting facial palsy even after six months. In contrast, peripheral facial palsy (PFP) occurs due to injury or damage to extra temporal segments of the facial nerve, for example, in idiopathic "Bell's" palsy, surgery such as mastoidectomy, or inflammation such as herpes zoster (Ramsay Hunt syndrome) (1).

\section{EPIDEMIOLOGY}

Facial nerve palsy is a frequent presentation to primary care providers, the emergency department, and otolaryngologists. The prevalence ranges between 23 to 35 cases per $1,00,000$, with Bell's palsy being the most common aetiology in $50 \%-75 \%$ of patients (2) . Trauma accounts for $10 \%$ to $23 \%$ of all facial nerve palsies. Facial nerve damage can be partial or complete; it can manifest immediately or in a delayed fashion. Late presentation is secondary 
to pressure effect from haemorrhage, oedema, or granulation tissue (3).

Irreversibility may be assumed if no signs of improvement occur within 18 months after the primary manifestation of FP (2).

\section{Effect on QOL}

Facial nerve injury has implications on a patient's quality of life due to the role the facial nerve has in multiple vital processes. In addition to the emotional impact of facial expression, facial nerve palsy can have ophthalmological, otological, rhinological, taste, and swallowing consequences. Ophthalmological consequences from impaired lacrimation, ectropion, and epiphora can lead to exposure keratopathy, leading to blindness. Otological effects include a reduction in hearing. Impaired muscular support to the nasal valve can lead to nasal obstruction. Impact on the perioral musculature can lead to poor swallowing and insufficient oral competence, while injury to the chorda tympani branch of the facial nerve can lead to impaired or altered taste (4). Electric stimulation of the face could potentially reduce these sequelae.

\section{Electrical stimulation (ES)}

The facial nerve can be enthused volitionally by the first motoneuron in the facial nerve nucleus or artificially by electro stimulation of the peripheral facial nerve. A series of action potentials is then induced, resulting in the depolarisation of the facial nerve between the nodes of Ranvier. The action potentials are conveyed to the facial muscles via the motor endplates. A motor unit (MU) comprises a facial motoneuron and its innervated muscle fibres. In small facial muscles, the number of muscle fibres per $\mathrm{MU}$ is low, making precise motor control of the muscles possible. The activation of the muscle fibres by its motor neuron results in a motor unit action potential (MUAP) (5).

Electrical stimulation is thought to lead to selectivity in the regeneration of motor nerves and reduced muscle atrophy. Selectivity means the nerves regrow and innervate a specific muscle, as opposed to nerves that regrow aberrantly and innervate several muscles making fine control of movement difficult and spasms more likely to occur. By stimulating muscles deprived of electrical nerve input, atrophy is prevented, and potentially muscles are more receptive to reinnervation. The theoretical benefits of electrical stimulation have been discussed extensively and replicated in laboratories, but the challenges have been in successfully incorporating electrical stimulation into the clinical setting.

A study on the reanimation of paralysed facial muscles by electrical stimulation was done by Makela et al. (6). Twenty-four subjects having peripheral facial nerve palsy for a median duration of three years were enrolled in the study. The researchers studied activations of four facial muscles using electrical stimulation with surface electrodes. In subjects whose voluntary movement was largely impaired or absent, the electrical stimulation resulted in a movement that was superior in amplitude as compared to the voluntary effort in 10 out of 18 patients in the frontalis muscle, in 5 out of 14 patients in the zygomaticus major muscle, and in 3 out of 8 patients in the orbicularis oris muscle. The electrical stimulation gave rise to a stronger blink in 8 patients out of 22 compared with their spontaneous blinks. The stimulation resulted in a better movement even in patients in whom the muscles were clinically totally paretic, sometimes also in palsies that were several years old, provided that the muscle was not totally denervated. The study concluded that reestablishing the function of paralysed facial muscles by electrical stimulation has potential as a therapeutic alternative in cases where the muscle is clinically paretic but has reinnervation (6).

Electrical stimulation has been successfully used in other parts of the body (7). Gordon et al. (8) used electrical stimulation acutely after injury to the median nerve for carpal tunnel syndrome patients with considerable axonal loss. Electrical stimulation is also used to accelerate nerve re- 
growth after facial nerve reparative surgery in animal models when a nerve transaction is being treated $(9,10)$.

\section{Delivery of ES}

Electrical stimulation is delivered transcutaneously by placing self-adhesive electrodes on the face. Electrical current is used to produce a visible contraction. The device is easily portable and weighs less than 8 ounces. Patients can pursue electrical stimulation treatment even on their own. The clinical community is divided over the usefulness of electrical stimulation, with some providers advocating its use while others strongly discouraging it (7). Clinicians discouraging it site concern for worse outcomes based on their observational experience and one study of the facial nerve of mice (11).

ES is one of the most controversial and nonevidence-based adjunctive therapies for FP (12). The indications for ES have been described as incomplete posttraumatic or postoperative peripheral nerve lesions, muscle atrophy, hyperkinesis, or synkinesis $(13,14,15)$. ES of muscle aims at preserving muscle bulk, especially in complete paralysis, and it also has a psychological benefit as the patient observes muscle contractions in his face that gives him hope for recovery from facial paralysis (16).

\section{REVIEW OF LITERATURE}

Farragher et al. (1987) (17) reported that individuals with long-standing Bell palsy ( 6 months to 50 years) might benefit from "eutrophic" ES added to a regimen of facial exercises and massage. However, the absence of a proper control group made it impossible to determine whether therapeutic benefits were related to $\mathrm{ES}$.

Adour (1991) (18) noted that facial nerve decompression and electrotherapy are not advised for the management of patients with Bell's palsy. This is in agreement with Wolf (1998) (19), who stated that ES should not be used in the treatment of Bell's palsy. Diels (2000) (20) stated that ES should not be used at any time in facial rehabilitation as there is evidence that it may be contraindicated, and it is unnecessary.

Targan et al. (2000) (21) investigated the efficacy of using pulsed ES to reduce neuromuscular conduction latencies and minimise clinical impairments in patients with long-standing facial nerve damage. They reported that patients with chronic Bell palsy who received ES showed improvements from moderately severe facial motor dysfunction (disfiguring asymmetry) to mild dysfunction (normal symmetry with only slight muscle weakness) at rest with slight mouth asymmetry and synkinesis during active contraction), but with little improvement in associated clinical problems (e.g., synkinesis, tearing, drooling). The sample size was small, and because all patients in this study received $E S$, the clinical improvements reported cannot be attributed to ES with confidence. Despite this, clinical improvements were observed in patients with Bell palsy whose dysfunction had persisted for a minimum of 3 months before the intervention, calling for a large randomised controlled trial that would meticulously test this ES protocol.

Goldie et al. (2016) (22) reported two case studies with marked facial weakness after resection of recurrent pleomorphic adenoma and their progress with electrical stimulation. Subjects received electrical stimulation twice daily for 24 weeks, during which photographs of expressions, facial measurements and Sunnybrook scores were recorded. Both subjects recovered good facial function, demonstrating Sunnybrook scores of 54 and 64 that improved to 88 and 96 . Neither subject demonstrated adverse effects of treatment. The study concluded that electrical stimulation was a safe treatment and may improve facial palsy in patients after resection of recurrent pleomorphic adenoma.

In 2020, three studies reported the use of electrical stimulation of facial muscles for latrogenic Facial Paralysis (23). The case series 
by Choi et al. (24) described three patients who achieved full recovery of facial function after treatment with physical therapy and electrical stimulation. The case series by Hussain et al. (25) reported using electrical stimulation alone in 2 patients after otologic surgery. Outcomes were described using the Facial Paralysis Recovery Profile and Recovery Index. Patients were treated for 60 weeks, and all demonstrated improvement. In the case series by Choi et al. (24) and by Hussain et al. (25), the method of electrical stimulation (percutaneous or transcutaneous) and the target muscles were not reported. In a retrospective cohort study, Gittins et al. (26) described transcutaneous electrical stimulation of the orbicularis oculi among eight patients with an HB grade of IV or worse after acoustic neuroma resection. Post-intervention HB grades were not reported. However, patients described some subjective improvement, including decreased use of artificial tears and improved facial tone. None of these three studies $(24,25,26)$ described specific synkinesis symptoms or worsening of synkinesis due to electrical stimulation.

A recent case report by Sommerauer et al. (2021) (27) highlighted the use of ES in attenuating the atrophy of mimic muscles when bridging the period between the first onset of FP and muscle-preserving surgery.

Seven published clinical trials have examined electrical stimulation of the face during acute Bell's palsy [Marotta et al. (2020) (28), Kim and Choi (2016) (29), Tuncay et al. (2015) (30), Alakram et al. (2010) (31), Manikandan et al. (2006) (32), Flores et al. (1998) (33) and Mosforth and Taverner (1958) (13)]. Five of these trials reported ES to be beneficial, albeit only weakly so $(28,29,30,33,33)$, and two found ES to provide neither benefit nor harm $(31,13)$. These trials were limited by their quality. They were small, underpowered,and most were not controlled (only three randomised controlled trials $(29,30,28)$. Patient factors predicting recovery, such as the initial severity of paralysis, age, duration of paralysis, and outcomes, were poorly reported.
Patient selection criteria in these studies was a concern. Often patients with incomplete paralysis were the only patients included in the study. $94 \%$ of patients with incomplete paralysis are expected to recover completely, in contrast to $61 \%$ of patients with complete paralysis, and only one-third of those over age 60 recover fully (34). Patients with complete paralysis who could benefit the most were often not included in these studies.

Varying ES parameters were used in the clinical trials. Most of the studies used current intensity sufficient to evoke muscle contractions, but one study used sub sensory level stimulation (29). The waveforms included biphasic $(31,32,33,28)$ and monophasic pulses (13,30). The outcome measures used in the studies also have substantial limitations. The most widely used measure of outcome, the House Brackmann (HB) scale, has low inter-rater reliability and does not adequately describe facial function (35).

Moreover, only one of the studies blinded the evaluators to group assignment (30) and only one blinded the participants (28). Tolerability, drop-out rates and adverse effects (AEs) were poorly reported or not reported at all. Spasms and synkinesis tend to develop six months or longer after the initial onset of paralysis in severe cases. The length of follow up in the studies has averaged three months which might likely underestimate late-onset sequelae and often is not reported (7). The length of therapy in some of the studies could be insufficient to see an effect. For example, Alakram et al. (31) only treated patients for 30 minutes weekly for three months, and Manikandan et al. (32) only treated patients three times per week for a total of two weeks. In severe cases of Bell's palsy, recovery may not begin for many months, making two weeks of electrical therapy potentially insufficient.

A literature search revealed several systematic reviews and (1) meta-analyses to investigate the role of ES in facial nerve palsy [ Burelo-Peregrino et al. (2020) (36), Fargher and Coulson(2017) (37), Quinn and Cramp (2014) (38), Teixeira et al. (2011) (39), Teixeira et al. (2008) (40), Buttress and 
Herren (2002) (41). One review concluded that there was no proof to support the use of ES during the acute phase of recovery after Bell's palsy, and there was low-level evidence for patients with chronic symptoms (37). None of the systematic reviews demonstrated homogeneous recommendations for ES due to a lack of quality evidence to support significant benefit or harm from ES. The different methodologies used and the small number of subjects included in the studies could not fully establish the efficacy of electrotherapy for treating facial nerve injury. These researchers opined that future studies with larger samples, homogenous populations, long duration and comparable methodologies were needed to ascertain conclusive results.

\section{CONCLUSION}

Many studies have reported improvement of facial movement or function following ES for facial nerve injury. But the quality of the evidence was low overall, and most studies were found to have a high risk of bias. Methodological limitations and heterogeneity of design affected the strength of the evidence and prevented reliable comparison between studies. Strong evidence supporting the use of ES in facial palsy is lacking; well-designed rigorous research is required.

\section{REFERENCES}

1. Vaughan A, Gardner D, Miles A, Copley A, Wenke R, Coulson S. A Systematic Review of Physical Rehabilitation of Facial Palsy. Front Neurol. 2020 Mar; 11(222).

2. Sommerauer L, Engelmann S, Ruewe M, Anker A, Prantl L, Kehrer A. Effects of electro stimulation therapy in facial nerve palsy. Arch Plast Surg. 2021; 48: p. 278-281.

3. Aziz K, Yu A, Chen D, R.F. SJ. Schmidek and Sweet Operative Neurosurgical Techniques. 6th ed.: Elsevier; 2012.

4. Mistry R, Al-Sayed A. Facial Nerve Trauma: StatPearls Publishing; 2021.

5. Guntinas-Lichius O, Volk G, Olsen K, Makities A, Silver C, Zafereo, et al. Facial nerve electrodiagnostics for patients with facial palsy: a clinical practice guideline. Euro Arch Oto Rhino Laryngol. 2020; 277: p. 1855-1874.
6. Makela E, Venesvirta H, Ilves M, Lylykangas J, Rantanen V, Yla-Kotola T. Facial muscle reanimation by transcutaneous electrical stimulation for peripheral facial nerve palsy. $J$ Med Engineering Tech. 2019 Jul; 43(3): p. 155164.

7. Oregon Health and Science University. [Online].; 2017 [cited 2021 Sep 28.

8. Gordon T, Amirjani N, Edwards D, Chan K. Brief post-surgical electrical stimulation accelerates axon regeneration and muscle reinnervation without affecting the functional measures in carpal tunnel syndrome patients. Exp Neurol. 2010 May; 223(1): p. 192-202.

9. Huang J, Zhang Y, Lu L, Hu X, Luo Z. Electrical stimulation accelerates nerve regeneration and functional recovery in delayed peripheral nerve injury in rats. Euro J Neuroscience. 2013 Dec; 38(12): p. 3691-3701.

10. Hadlocl T, Lindsay R, Edwards C, Smitson C, Weinberg J, Knox C, et al. The effect of electrical and mechanical stimulation on the regenerating rodent facial nerve. Laryngoscope. 2010;120(6): p. 1094 -1102.

11. Skorasa E, Merkelb D, Groshevac M, Angelovac S, Schiffera $G$, Thelena $U$, et al. Manual stimulation, but not acute electrical stimulation prior to reconstructive surgery, improves functional recovery after facial nerve injury in rats. Restrorative Neurol Neuroscience. 2009; 27: p. 237-251.

12. Paternostro-Sulga T, Herceg M, Frey $M$. Conservative treat $\neg$ ment and rehabilitation in peripheral facial palsy. Handchir Mikrochir Plast Chir. 2010; 42: p. 109-14.

13. Mosforth J, Taverner D. Physiotherapy for Bell's palsy. Br Med J. 1958; 2: p. 675-7.

14. Paternostro-Sulga T, Herceg M, Frey M. Conservative treatment and rehabilitation in peripheral facial palsy. Handchir Mikrochir Plast Chir. 2010; 42: p. 109-14.

15. Eviston T, Croxson G, Kennedy P. Bell's palsy: ae $\neg$ tiology, clinical features and multidisciplinary care. J Neurol Neurosurg Psychiatry. 2015; 86: p. 1356-61.

16. Shafshak T. The treatment of facial palsy from the point of view of physical and rehabilitation medicine. Eur Med. 2006; 42: p. 41-7. 
17. Farragher D, Kidd G, Tallis R. Eutrophic electrical stimulation for Bell's Palsy. Clin Rehabili. 1987; 1: p. 265-271.

18. Adour K. Medical management of idiopathic (Bell's) palsy. Otolaryngol Clin North Am. 1991; 24(3): p. 663-673.

19. Wolf S. Idiopathic facial paralysis. HNO. 1998; 46(9): p. 786-798.

20.Diels H. Facial paralysis: is there a role for a therapist? Facial Plast Surg. 2000; 16: p. 3614.

21. Targan R, Alon G, Kay S. Effect of long-term electrical stimulation on motor recovery and improvement of clinical residuals in patients with unresolved facial nerve palsy. Otolaryngol Head Neck Surg. 2000; 122: p. 246-252.

22. Goldie S, Sandeman J, Cole R, Dennis S. Electrical stimulation treatment for facial palsy after revision pleomorphic adenoma surgery. J Surg Case Rep. 2016; 4: p. 1-4.

23. Wamkpah N, Jeanpierre L, Lieu J, Toro D, Simon L, Chi J. Physical Therapy for latrogenic Facial Paralysis: A Systematic Review. JAMA Otolaryngol Head Neck Surg. 2020 Nov; 146(11): p. 1065-1072.

24. Choi B, Goh R, Chen P, Chuang D, Lo L, Chen Y. Facial nerve palsy after sagittal split ramus osteotomy of the mandible: mechanism and outcomes. J Oral Maxillofac Surg. 2010; 68(7): p. 1615-1621.

25. Hussain S, Winterburn S, Grace A. Eutrophic electrical stimulation in long-standing facial palsy. Eur Arch Otorhinolaryngol. 1994;: p. S133-S134.

26. Gittins J, Martin K, Sheldrick J, Reddy A, Thean L. Electrical stimulation as a therapeutic option to improve eyelid function in chronic facial nerve disorders. Invest Ophthalmol Vis Sci. 1999; 40(3): p. 547-554.

27. Sommerauer L, Engelmann S, Ruewe M, Anker A, Prantl L, Kehrer A. Effects of electrostimulation therapy in facial nerve palsy. Arch Plast Surg. 2021; 48: p. 278-281

28. Marotta N, Demeco A, Inzitari M, Caruso M, Ammendolia A. Neuromuscular electrical stimulation and shortwave diathermy in unrecovered Bell palsy: a randomised controlled study. Medicine. 2020; 99(8): p. e19152.

29. Kim J, Choi J. The effect of subthreshold continuous electrical stimulation on the facial function of patients with Bell's palsy. Acta Otolaryngol. 2016; 136: p. 100-105.

30. Tuncay F, Borman P, Taser B, Unlu I, Samim E. Role of electrical stimulation added to conventional therapy in patients with idiopathic facial (Bell) palsy. Am J Phys Med Rehabil. 2015 Mar; 94(3): p. 222-8.

31. Alakram P, Puckree T. Effects of electrical stimulation on House-Brackmann scores in early Bell's palsy. Physiother Theory Pract. 2010 26; 3: p. 160-166.

32.Manikandan N. Effect of facial neuromuscular re-education on facial symmetry in patients with Bell's palsy: a random-ized controlled trial. Clin Rehabil. 2007; 21: p. 338-43.

33.Flores P, Zazueta M. Idiopathic peripheral facial paralysis treatment physical therapy versus prednisone. Revista Medica Del Instituto Mexicano Del Seguro Social. 1998; 36: p. 217-221.

34.Peitersen E. Bell's palsy: the spontaneous course of 2,500 peripheral facial nerve palsies of different etiologies. Acta Otolaryngol Suppl. 2002;: p. 4-30.

35. Loyo M, McReynold M, Mace J, Cameron M. Protocol for randomised controlled trial of electric stimulation with high-volt twin. J Rehabilitation and Assistive Technologies Engineering. 2020; 7: p.1-7.

36. Burelo-Peregrino E, Salas-Magana M, AriasVazquez P. Efficacy of electrotherapy in Bell's palsy treatment: A systematic review. J Back Musculoskelet Rehabil. 2020 Feb.

37. Fargher K, Coulson S. Effectiveness of electrical stimulation for rehabilitation of facial nerve paralysis. Physical Trerapy Rev. 2017 Aug; 22(3): p. 169-176.

38. Quinn R, Cramp F. The Efficacy of Electrotherapy for Bell's Palsy: A Systematic Review. Physical Therapy Rev. 2003; 8(3): p. 151-164.

39. Teixeira L, Valbuza J, Prado G. Physical therapy for Bell's palsy (idiopathic facial paralysis). Cochrane Database Sys Rev. 2011; 
12: p. CD006283.

40. Teixeira L, Soares B, Vieira V, Prado G. Physical therapy for Bell's palsy (idiopathic facial paralysis). Cochrane Database Syst Rev. 2008; 3: p. CD006283.

41. Buttress S, Herren K. Towards evidence based emergency medicine: best BETs from the Manchester Royal Infirmary. Electrical stimulation and Bell's palsy. Emerg Med J. 2002; 19: p. 428.

\section{*Corresponding Author:}

Dr Sanyukta Chakravorty

Postgraduate Junior Resident second year;

Department of E.N.T., Mayo Institute of Medical

Sciences, Barabanki 